\title{
A docência em Filosofia no contexto da profissão docente no país: aspectos conjunturais e reflexão filosófica ${ }^{1}$
}

Christian Lindberg Lopes do Nascimento ${ }^{2}$

\begin{abstract}
Resumo:
O objetivo deste artigo é retratar informações referentes à profissão docente, expondo, sempre que possível, elementos que reflitam a realidade da docência em Filosofia no país. A investigação, que surgiu da necessidade de suprir uma lacuna existente nos estudos sobre o perfil do docente, especificamente do de Filosofia, partiu da seguinte questão: Que elementos caracterizam a docência em nosso país, e de forma específica a de Filosofia? A argumentação percorre o seguinte traçado. Em um primeiro momento são expostos alguns dados referentes à docência no Brasil. Em seguida, explora-se a reflexão filosófica que Adorno desenvolveu em torno da profissão docente. Do ponto de vista metodológico, o texto contempla elementos quantitativos e qualitativos, sendo a análise de conteúdo o procedimento adotado.
\end{abstract}

Palavras-chave: Ensino de Filosofia. Formação docente. Teoria crítica.

\begin{abstract}
:
This article aims to expose a diagnosis of the philosophy teacher, not rulling out the use of some general information regarding the profession of teacher. The investigation, which came from the need to fill a gap existing in the the studies on philosophy teaching, arrised from the following question: which is the profile of the philosophy teacher? Some qualitative and quantitative data were considered, as well as the reflection that Adorno made about teaching. From the methodological point of view, the text contemplates the concern exposed by the critical theory when it announces that the diagnosis of situation is fundamental to identify the emancipatory potentil in society.
\end{abstract}

Key words: Philosophy teaching, teacher training, Critical theory.

\footnotetext{
${ }^{1} \mathrm{O}$ texto é fruto de um trabalho apresentado durante o IV Encontro do GT Filosofar e ensinar a filosofar da ANPOF, evento realizado entre os dias 8 e 10 de novembro de 2017, no campus da Universidade Federal de Campina Grande Paraíba (UFCG).

${ }^{2}$ Professor adjunto do Departamento de Filosofia (UFS). Integra o corpo docente do programa de pós-garduação em Filosofia da UFS e do mestrado profissional em Filosofia (UFPE). Membro do GT Filosofar e ensinar a filosofar da ANPOF.
} 
Refletir sobre a docência em Filosofia requer, antes de tudo, analisar elementos da realidade educacional, especialmente daquela que se relaciona com a formação e valorização docente no país. Embora não seja comum o uso de elementos quantitativos nas reflexões filosóficas, a Teoria crítica procura identificar, além do potencial emancipatório existente na sociedade, o diagnóstico de situação. Como diz o professor Marcos Nobre (2008, p.12), no livro Curso Livre de Teoria Crítica: "É decisivo para a Teoria Crítica a análise das estruturas sociais reais em que estão inscritos tanto os potenciais de emancipação quanto os obstáculos concretos à sua efetivação" e acrescenta:

O diagnóstico do presente tem de ser produzido em razão das possibilidades de libertação da dominação do capital, à luz da emancipação possível que o capitalismo carrega dentro de si. Por isso, a teoria tem de estar em união com a prática transformadora que lhe dá seu pleno sentido. (Nobre, 2008, p.13)

De posse desse marco conceitual com impacto metodológico, o objetivo deste artigo é contribuir com a reflexão que gira em torno da profissão docente, particularmente com a de Filosofia. Para tanto, serão destacadas algumas informações, a exemplo dos estudos realizados por órgãos oficiais do governo, como também pesquisas desenvolvidas no campo da formação docente. Além dos aspectos quantitativos e qualitativos, a argumentação encontrará na reflexão filosófica desenvolvida por Theodor Adorno uma fonte fundamental para que esta empreitada intelectual cumpra seu desígnio.

Parte-se da constatação contida no Censo Educacional do Ensino Superior (2016) que registra o fato de o Brasil possuir 8.048.701 graduandos. Destes, 18,57\% estão matriculados na modalidade a distância $(\mathrm{EaD})$ e os demais em cursos presenciais. No caso específico das licenciaturas, há 1.520.494 estudantes, sendo que o curso de Filosofia 
atende 20.147 matriculados, ou seja, $0,25 \%$ dos estudantes de graduação de todo o país ou $1,3 \%$ dos licenciandos, número relativamente baixo.

Ao analisar os dados da licenciatura, observa-se que $38,1 \%$ dos matriculados estudam em Instituições de Ensino Superior (IES) públicas e os demais $61,9 \%$ em IES privadas. Do total de licenciandos, 57,9\% frequentam cursos presenciais e os demais $42,1 \%$ a modalidade $\mathrm{EaD}$, o que equivale a 640.128 estudantes. Contudo, esta realidade se inverte quando analisamos os licenciados matriculados exclusivamente nas IES privadas: $59,3 \%$, ou seja, a ampla maioria.

Observa-se, assim, que a maior parte dos licenciandos está matriculada em IES privadas, algo em torno de 941 mil estudantes, sendo que a modalidade $\mathrm{EaD}$ contempla aproximadamente 558 mil discentes. $\mathrm{O}$ presente cenário aponta para a seguinte perspectiva: se por um lado os futuros professores estarão adaptados ao ambiente virtual, por outro, eles trarão consigo os limites que esta modalidade de ensino transmite aos seus egressos.

No quesito condições de trabalho, pode-se extrair as seguintes informações do Censo da Educação Básica (2016). Foi constatado que existem 488.064 professores no ensino médio, sendo que 93,5\% deles têm nível superior. Quanto à jornada de trabalho diária em sala de aula no ensino médio, o mesmo estudo revela que cada docente trabalha, em média, 4,9h/dia, em sala de aula, sendo que a rede federal possui a maior jornada (6,7h/dia) e a municipal, talvez por questões constitucionais, a menor (4,7h/dia). É bom destacar que a Lei do Piso Nacional do Magistério determina que a carga horária de trabalho do professor seja de $40 \mathrm{~h} / \mathrm{semanais}$ e que não ultrapasse $2 / 3$ deste tempo em sala de aula.

Do ponto de vista da remuneração, estudo divulgado pelo Instituto Nacional de Estudos e Pesquisas Educacionais Anísio Teixeira (INEP), em junho de 2017, com base nos próprios dados e nos coletados no sistema RAIS/Ministério do Trabalho e Emprego, constatou que 99\% dos professores com carga horária de 40h/semanais, ganham menos do que 3,5 mil reais por mês. A média de remuneração mais baixa é a dos docentes que 
trabalham em escolas particulares, que gira em torno de $\mathrm{R} \$ 2.599,33$ por mês. Na rede municipal, onde atua metade dos professores de todo o país, a média da remuneração é de $\mathrm{R} \$ 3.116,35$. Na estadual, os professores recebem em média o equivalente a $\mathrm{R} \$ 3.476,42$ mensais. ${ }^{3}$ Os professores da rede federal são os mais bem pagos do país: eles recebem em média $\mathrm{R} \$$ 7.767,94 por mês. Esta disparidade salarial tende a colaborar com o mapeamento dos professores que atuam no país. Os mais titulados são atraídos pelos melhores salários e condições de trabalho, impactando na qualidade do ensino. Por outro lado, mesmo após a instituição do Piso Nacional dos Professores, constata-se que muitos Estados e municípios alteram o plano de carreira dos docentes e/ou desrespeitam a legislação federal.

O IPEA também tem estudos sobre a realidade do professor brasileiro. No Radar $\mathrm{n}^{\circ}$ 32, intitulado Tecnologia, produção e comércio exterior, publicado em 2014, o instituto destaca que cerca $25 \%$ dos docentes das escolas públicas com regência de classe mantêm com o poder público contratos temporários ou são terceirizados. A precarização no vínculo do trabalho docente é um problema acentuado na educação básica. No caso específico do ensino médio, a proporção de docentes terceirizados ou com vínculos temporários nas redes estaduais ultrapassa a casa dos 30\%, chegando a ser mais de $40 \%$ em algumas disciplinas.

O relatório da OCDE, Education at a Glance, de 2017, registra que o professor brasileiro tem em média 40 anos, enquanto que nos países membros da OCDE essa média fica entre 44 e 45 anos. No Brasil, $80 \%$ de todos os professores têm menos de 50 anos, enquanto a média internacional é de $65 \%$. Diagnosticar a faixa etária dos docentes que atuam na educação básica auxilia na elaboração de políticas públicas, mais especificamente quando permite estabelecer ações de formação continuada de médio e longo prazo.

Os indicadores sociais e econômicos apresentados auxiliam a traçar um perfil médio do professor brasileiro. Geralmente ele tem uma jornada de

${ }^{3}$ Segundo o DIEESE, o salário mínimo deveria ser de R \$ 3.731,39 no mês de novembro de 2017, valor 4 vezes maior do que o salário mínimo vigente no referido mês.

Filos. e Educ., Campinas, SP, v.10, n.2, p.310-330, maio/ago. 2018 - ISSN 1984-9605 
trabalho em torno de $5 \mathrm{~h}$ por dia em sala de aula, ganha 3,5 mil reais por mês, tem 40 anos de idade e possui nível superior. Dois outros dados merecem destaque: 1) Do ponto de vista das relações trabalhistas, observase que $1 / 3$ dos professores que lecionam ensino médio e trabalham na rede estadual têm vínculo precário ${ }^{4}$; 2) Os docentes da rede particular são os que possuem a menor média salarial por mês.

Quando se olha para dentro da sala de aula percebe-se que a realidade é mais complicada do que se imagina. O documento do Ministério da Educação (MEC) denominado Censo Educacional 2013: perfil da docência no ensino médio regular, divulgado no final de 2015, destaca o déficit de 256.746 professores nas salas de aula em todo o país, o que tende a impactar na qualidade da educação que é ofertada nesse nível de ensino.

No caso específico da Filosofia, este estudo revela que há a necessidade de se contratar 16.780 novos docentes ${ }^{5}$. Por outro lado, identifica que existem 45.104 docentes de Filosofia no ensino médio regular, dos quais $14,6 \%$ (6.602) lecionam apenas esta disciplina. 21,8\% dos professores que lecionam Filosofia possuem formação específica e, entre os docentes que ensinam Filosofia, mas não têm formação específica, as áreas que mais aparecem são História, Pedagogia e Ciências Sociais ${ }^{6}$.

Se as pesquisas oficiais detectam o déficit de docentes de Filosofia no ensino médio regular, o Censo do Ensino Superior (2016) observou que, em 2006, 24,8\% dos alunos concludentes do ensino superior cursavam licenciaturas. Em 2016, esse número caiu para 20,43\%, ou seja, houve uma redução percentual no número de professores formados em nosso país. No caso dos ingressantes, em 2006, 22,2\% ingressaram em cursos de licenciatura. Dez anos depois este número caiu para 19,96\%. Em outros termos, os cursos de licenciatura estão formando menos de professores e não conseguindo atrair jovens para a profissão docente.

\footnotetext{
${ }^{4}$ É bom registrar que estes dados foram coletados antes da aprovação da Reforma trabalhista e da Emenda Constitucional $\mathrm{n}^{\circ} 95$.

${ }^{5}$ Esta projeção foi feita considerando a carga horária de 2h/semana de Filosofia.

${ }^{6} \mathrm{O}$ dado mais recente do MEC aponta que $31 \%$ dos docentes que lecionam Filosofia são formados em Filosofia (Licenciatura ou bacharelado com curso de complementação pedagógica concluído).
} 
Após destacar alguns indicadores referentes ao quantitativo de licenciandos, perfil docente e questões salariais/trabalhistas, é oportuno elencar outras informações, tendo em vista um diagnóstico de situação mais preciso e que sirva para balizar a reflexão em torno da docência em Filosofia. Estudo publicado em abril de 2016 pelo Instituto Alfa\&Beta constatou uma média baixa, inferior a 50 pontos, nas provas de conhecimentos gerais realizadas pelos estudantes de licenciatura no ENADE, ${ }^{7}$ o que sinaliza que poucos graduandos têm nível cultural geral desejável para um egresso do ensino superior, o que tende a repercutir em sala de aula.

Outrossim, além do aspecto quantitativo, a realidade dos cursos de licenciatura aponta para uma formação debilitada. Em artigo publicado na revista Educar em revista, a professora Bernadete Gatti (2013, p.58) concluiu que:

a) Há grande dissonância entre os Projetos Pedagógicos dos cursos e a estrutura do conjunto de disciplinas e suas ementas, parecendo que aqueles são documentos que não repercutem na realização dos cursos; b) O currículo proposto pelos cursos de formação de professores tem uma característica fragmentária; c) A proporção de horas dedicadas às disciplinas referentes à formação profissional docente, nas licenciaturas em pedagogia fica em torno de $30 \%$, e, nas demais licenciaturas, essa proporção fica entre $10 \%$ e 15\% para as disciplinas da educação; d) $\mathrm{Na}$ análise das ementas das disciplinas de formação profissional (metodologias e práticas de ensino, por exemplo) também predominam apenas referenciais teóricos sem associação com práticas educativas; e) $\mathrm{O}$ currículo da educação básica praticamente não aparece nas formações propostas; f) Raras instituições especificam em que consistem os estágios e sob que forma de orientação, acompanhamento e avaliação são realizados; g) A questão das

\footnotetext{
${ }^{7}$ A prova de conhecimentos gerais normalmente está mais associada ao nível cognitivo dos alunos do que a aprendizagens específicas adquiridas durante o curso. Ela varia de 0 a 100 pontos.
}

Filos. e Educ., Campinas, SP, v.10, n.2, p.310-330, maio/ago. 2018 - ISSN 1984-9605 
Práticas, exigidas pelas diretrizes curriculares dos cursos, mostra-se problemática, pois às vezes se coloca que estão embutidas em diversas disciplinas, sem especificação clara; h) Um grupo considerável de matrizes curriculares apresenta disciplinas pouco específicas quanto a seus nomes e, com ementas bastante ligeiras; i) Aparecem nos currículos muitas horas dedicadas a Atividades Complementares, Seminários ou Atividades Culturais etc., que ficam sem nenhuma especificação quanto a que se referem; e j) Uma parte dessas licenciaturas promove especialização precoce em aspectos que poderiam ser abordados em especializações ou pós-graduação.

O caso da licenciatura em Filosofia não é tão diferente. No que pese o impacto do PIBID e do estágio supervisionado na formação inicial dos futuros professores, Silvio Gallo (2012) alerta para o fato de que um dos principais problemas existentes na formação inicial do docente de Filosofia, no Brasil, é a ênfase na constituição de um egresso que domine os requisitos pertinentes a um bacharel. Por outro lado, mesmo com disciplinas pedagógicas no currículo, observa que elas são tratadas de forma separada, muitas vezes secundarizadas. Para ele, este tipo de formação joga por terra todo o esforço na tentativa de articular teoria e prática, considerando as atuais normas que impõem a carga horária específica para o estágio supervisionado de $420 \mathrm{~h}$ no decorrer da licenciatura.

Paula Ramos aborda esta cultura bacharelesca, que predomina em certas faculdades/departamentos de Filosofia, em um de seus artigos. Ela parte de duas premissas interessantes: 1) A de que existe uma histórica separação entre bacharelado e licenciatura; 2) Ensinar e aprender Filosofia são questões inerentes ao campo filosófico. Com isso, sentencia:

Mesmo a partir de uma visão pouco problematizadora acerca do ensinar e do aprender em filosofia, o bacharelando deve lidar com o aprender filosofia em seu curso de graduação e caso venha a se tornar um professor do ensino superior terá que enfrentar o ensino de filosofia que, até então, parece unicamente objeto daqueles que irão 
ministrar aulas no Ensino Médio ou, poderíamos também dizer, na Educação Básica. (Oliveira, 2015, p.228)

Os resultados das pesquisas apresentadas revelam informações importantes para se pensar no perfil do professor que atua na educação básica, especialmente no ensino médio, como também auxiliam na compreensão de alguns aspectos relacionados ao docente de Filosofia. Contudo, o aspecto conjuntural aponta à necessidade de incluir mais quatro fatores que têm deixado professores, pesquisadores em educação e licenciandos em estado de apreensão. São eles: 1) O denominado projeto Escola sem partido; 2) A violência escolar; 3) O processo de uberização da carreira docente; 4) A Política Nacional de Formação de Professores. Vou me ater às três últimas.

A Plataforma digital $Q E d u$, que é mantida pela Fundação Lemman, contabilizou, com base em dados obtidos na Prova Brasil, mais de 22,6 mil ameaças por parte dos estudantes aos professores e mais de 4,7 mil atentados à vida de docentes nas escolas em que lecionam. Mais de 2,3 mil professores afirmaram que estudantes frequentaram as aulas com armas de fogo e mais de 12 mil disseram que havia alunos com armas brancas, como facas e canivetes ${ }^{8}$.

Esta realidade de violência no ambiente escolar reflete, em certo grau, a que ocorre na sociedade. Além do país viver uma escalada de violência nos últimos anos, estudo realizado com jovens infratores no Rio Grande do Sul e publicado no livro A formação de jovens violentos: estudo sobre a etiologia da violência extrema (2016) revela que a própria escola dá sua contribuição à violência. Foi observado que a evasão escolar, ainda no ensino fundamental, é alta entre eles, como também a defasagem na relação idade/série.

Outro fator que conduz o jovem ao mundo do crime é o que Marcos Rolim, autor do livro, identifica como processo especial de socialização,

${ }^{8}$ Os dados são do questionário da Prova Brasil 2015, aplicado a diretores, alunos e professores do $5^{\circ}$ e do $9^{\circ}$ ano do ensino fundamental de todo o país.

Filos. e Educ., Campinas, SP, v.10, n.2, p.310-330, maio/ago. 2018 - ISSN 1984-9605 
situação que é viabilizada pela presença de grupos armados que explora a venda de drogas ilícitas, garantindo um ganho fácil ou de acúmulo de bens aos jovens, garantindo-lhes a possibilidade de autoria, respeito e poder. "O que o jovem abandona é a promessa, talvez excessivamente abstrata, de uma vida melhor construída pelo estudo e pelo trabalho." (Rolim, 2016).

A outra questão diz respeito ao que tem sido denominado de uberização da profissão docente. Em meados de 2017, a Secretaria Municipal de Educação de Ribeirão Preto, interior do estado de São Paulo, apresentou uma minuta de projeto de lei com o objetivo de contratar professores substitutos para ministrarem aulas avulsas, especialmente nos casos de falta dos efetivos. Esses docentes seriam convocados por celular, whats app e redes sociais (twitter, facebook, instagram, etc.). O que parece ser uma ideia interessante é, na verdade, uma forma de precarizar as relações trabalhistas, desvalorizando mais ainda a carreira docente. De imediato, o Conselho Municipal de Educação da cidade rejeitou a ideia, com base nos seguintes argumentos:

1) A proposta apresenta-se pífia desde o ponto de vista do planejamento, pois não se fundamenta em dados concretos; 2) No tocante a ciência pedagógica, ignora-se todo o acúmulo científico acerca das dificuldades próprias do exercício da docência em substituição; 3) Em relação a qualidade da educação, propõe-se solução simplesmente inaceitável do ponto de vista qualitativo, oferecendo, aos alunos, docentes eventuais que, embora se diga atenderão a requisitos mínimos de formação, serão sempre pessoas que a isto recorrerão em razão da situação de absoluto desemprego; 4) Do ponto de vista laboral, cria-se a figura com vínculo extremamente precário no sistema, com potencial para ter seu uso ilicitamente expandido no futuro; 5) Do ponto de vista jurídico-constitucional, eis que se cria função pública de caráter eventual para atender a necessidade não eventual da Administração. (CME/Ribeirão Preto, 2017, p.09) 
A última diz respeito à nova Política Nacional de Formação de Professores, divulgada em março de 2018, aparece no meio da implantação da resolução $n^{\circ}$ 02/2015/CNE. Ela também acolhe os princípios estabelecidos na Constituição Federal, na LDB e no Plano Nacional de Educação (PNE) ${ }^{9}$, em particular as metas 15 e 16. Importante lembrar que o PNE alude a quatro metas para a área de formação e valorização da carreira docente, e, justamente aquelas relacionadas ao plano de carreira e piso nacional, foram desprestigiadas pelos dirigentes do MEC.

No diagnóstico feito para balizar as políticas públicas elencadas, os gestores do MEC afirmam que: "Evidências mostram que, entre os fatores que podem ser controlados [grifo meu] pela política educacional, o professor é o que tem maior peso na determinação", e promovem o seguinte diagnóstico: 1) Resultados insuficientes dos estudantes, desigualdades aumentaram; 2) Baixa qualidade da formação de professores; 3) Currículos extensos que não oferecem atividades práticas; 4) Poucos cursos com aprofundamento da formação na educação infantil e no ciclo da alfabetização; 5) Estágios curriculares sem planejamento e sem vinculação clara com as escolas.

Embora o diagnóstico apresente elementos relevantes, quando afirma que existe uma baixa qualidade na formação inicial dos professores, ele expõe verdades sem nenhum embasamento científico, sentenciando que os atuais estágios curriculares são feitos sem planejamento e sem vínculo com

${ }^{9}$ Meta 15: Garantir, em regime de colaboração entre a União, os Estados, o Distrito Federal e os Municípios, no prazo de 1 (um) ano de vigência deste PNE, política nacional de formação dos profissionais da educação; Meta 16: Formar, em nível de pós-graduação, $50 \%$ (cinquenta por cento) dos professores da educação básica, até o último ano de vigência deste PNE, e garantir a todos os(as) profissionais da educação básica formação continuada em sua área de atuação; Meta 17: Valorizar os(as) profissionais do magistério das redes públicas de educação básica de forma a equiparar seu rendimento médio ao dos(as) demais profissionais com escolaridade equivalente, até o final do sexto ano de vigência deste PNE; Meta 18: Assegurar, no prazo de 2 (dois) anos, a existência de planos de carreira para os(as) profissionais da educação básica e superior pública de todos os sistemas de ensino. [grifo meu].

Filos. e Educ., Campinas, SP, v.10, n.2, p.310-330, maio/ago. 2018 - ISSN 1984-9605 
as escolas. De igual modo, não apresenta nenhum estudo que balize a dimensão teórica das licenciaturas, principalmente porque o MEC avalia que o currículo defende um perfil mais teórico do que prático na formação inicial do professor.

A solução apontada pela Política Nacional de Formação Docente para a formação inicial consiste em: 1) Estabelecimento de uma Base Nacional de Formação Docente, a ser divulgada em 2018; 2) Programa de residência pedagógica, que inclui a modernização do PIBID e a concessão de 80 mil bolsas; 3) Destinação de $75 \%$ das vagas da Universidade Aberta do Brasil (UAB) para a formação de professores para a $1^{\mathrm{a}}$ e $2^{\mathrm{a}}$ licenciaturas; 4) Estabelecer políticas de indução para que o PROUNI preencha as $20 \mathrm{mil}$ vagas ociosas nos cursos de licenciatura, visando colaborar com o esforço de formar mais docentes (especialmente para a $2^{\circ}$ licenciatura). Não custa lembrar que a Base Nacional Comum Curricular para o ensino médio (BNCC/EM) também induzirá a Política Nacional de Formação Docente.

Ora, observa-se que a falta de profissionais e a queda no número de docentes formados e de ingressantes nos cursos de licenciatura apontam para um futuro tenebroso, o que tende a impactar no funcionamento dos cursos de formação docente e na educação básica em curto e médio prazo. Além disso, a questão salarial, a precarização da carreira docente, as limitações na formação e o debate conjuntural aumentam os obstáculos a serem superados. Como bem registra Junot Cornélio de Matos, no livro $A$ formação pedagógica dos professores de filosofia: um debate, muitas vozes:

$\mathrm{Na}$ atual conjuntura, os cursos de formação de professores vivem uma situação difícil. Critica-se a qualidade da maioria desses cursos, alega-se que não há demanda para eles, porque não há mercado, falase dos salários baixos e das precárias condições de trabalho, como se estes fossem obras de um acaso. (Matos, 2013, p.40)

Embora os dados - qualitativos e quantitativos da profissão docente aqui arrolados não ajudam a caracterizar o perfil exato do professor de Filosofia em nosso país, como foi dito, ao menos ajudam a construir um 
cenário aproximado. Sabe-se, por exemplo, que existem poucos licenciandos de Filosofia no país, como também há um déficit de profissionais na rede pública, notadamente no ensino médio. A cultura bacharelesca continua prevalecendo nos cursos de licenciaturas, ainda que haja incremento de programas voltados para a formação docente, como o PIBID e o estágio curricular obrigatório.

O diagnóstico de situação apresentado esboça elementos importantes para se pensar na profissão docente. No entanto, a reflexão filosófica em torno do professor de Filosofia encontra em alguns textos de Adorno o ambiente propício para o pensar filosoficamente à docência de Filosofia. No texto intitulado A Filosofia e os professores, o referido autor desenvolveu uma reflexão em torno da realidade dos professores alemães que prestaram concurso para lecionar Filosofia nas escolas de Hessen.

A inquietação adorniana deixa-o apreensivo em relação aos objetivos do exame, com a constatação de que os postulantes podem ser divididos em dois grupos - estudantes dotados de sensibilidade intelectual e candidatos que demonstram certo interesse pela Filosofia -, o que leva o frankfurtiano a perceber os limites da seleção.

O primeiro grupo de candidatos, embora detenha sensibilidade para a reflexão filosófica, é mal avaliado porque a prova é pautada pela fragmentação dos conteúdos, convertendo-se em uma avaliação eminentemente tecnicista. Os candidatos do outro grupo, por mais que tenham interesse pela Filosofia e são aprovados, não possuem uma formação inicial sólida, o que tende a trazer sérios prejuízos para a aprendizagem dos futuros alunos.

Além destas duas deficiências, o exame detecta outros problemas na formação docente. É comum, segundo Adorno, misturar a linguagem formal com a informal nos textos do concurso, o que expressa falta de domínio do vernáculo. Há também, ainda no campo da escrita, erros de grafia, especialmente quando se escreve o nome de filósofos de outros países. Nas duas situações, ele analisa que há certa negligência dos postulantes com a linguagem ou a simples incapacidade de escrever corretamente. 
Entretanto, a principal rejeição adorniana ao exame de admissão diz respeito ao caráter estritamente técnico dado aos conteúdos filosóficos, não havendo nenhum espaço para examinar se o postulante tem uma formação cultural apropriada para o futuro exercício profissional. Esta característica impressa na prova é oposta à defendida por ele. Segundo Adorno, em um concurso para professor de Filosofia:

A prova geral, na medida em que isto é possível para um exame, pretende avaliar se os candidatos conseguem ir além do seu aprendizado profissional estrito, na medida em que desenvolvem uma reflexão acerca de sua profissão, ou seja, pensam acerca do que fazem, e também refletem acerca de si mesmos. (Adorno, 2003, p.54)

O frankfurtiano destaca que boa parte escolhe a carreira profissional de professor por causa dos conselhos familiares. Isto ocorre a medida que os membros da família percebem a incapacidade dos mais jovens em lograr carreiras que requeiram títulos melhores. Na Alemanha vivida por Adorno havia certo desprezo pela profissão de professor, acarretando certa resignação naqueles que optavam por ela, ou seja, a docência tendia a ser ocupada pelos jovens menos capacitados.

Como se observa, a crítica adorniana ao exame de admissão para a carreira docente traz consigo deficiências - a exemplo do seu caráter estritamente técnico -, além de identificar os limites existentes na própria formação inicial do professor como a dificuldade em dominar elementos linguísticos. O perfil técnico da avaliação impede a percepção do espírito reflexivo e crítico do postulante, característica fundamental, segundo Adorno, para os futuros professores de Filosofia.

Em outro texto voltado para a reflexão em torno da profissão de professor - Tabus a respeito do professor -, Adorno estabelece o diagnóstico da situação e expõe algumas preocupações com o futuro docente. Embora admita que não tem a pretensão de elaborar uma teoria, muito menos a de relatar o resultado de uma pesquisa empírica, o eixo central deste ensaio é tentar compreender os motivos que caracterizam certo tabu existente em 
torno da docência, particularmente diante da barbárie vivida pela Alemanha na primeira metade do século passado.

Adorno (2008, p.158) detectou que é "entre os melhores estudantes, após a aprovação dos exames oficiais, que se encontra a maior aversão contra a profissão para qual os exames qualificam e que fica à disposição deles." Assim, Adorno identifica que os selecionados a ingressarem em cursos de formação docente encaram a futura profissão com certo descrédito devido a uma suposta remuneração baixa. No entanto, a realidade salarial desmente a existência de uma situação de penúria entre os professores.

Para reforçar seu argumento, afirma que a sociedade valoriza com ressalvas a profissão de professor, algo que não ocorre quando ela é comparada com a carreira jurídica e a médica, pois estas têm apelo social inquestionável. Esta situação é mais um elemento, segundo Adorno, que caracteriza o tabu existente em torno da docência.

Outro fator destacado pelo frankfurtiano aparece quando se compara o professor da educação básica com o do ensino superior. Adorno observa que a aversão ao primeiro persiste e conclui que a função de magistério na educação básica é cercada de um certo tabu no interior da sociedade alemã, entendida por ele como:

Representações inconscientes ou pré-conscientes dos que se candidatam a essa profissão - mas também dos demais, em especial das próprias crianças - que se impõem como uma espécie de interdição psíquica a essa profissão e que lhe levantam dificuldades, das quais raramente se alcança uma ideia clara. Portanto, emprego o conceito tabu num sentido mais rigoroso como a sedimentação coletiva de representações que, de maneira similar às de caráter econômico que mencionei, perderam sua base em grande medida mas que, como preconceitos sociais e psicológicos, persistem teimosamente e, por sua vez, tornam-se forças atuantes na realidade, tornam-se forças reais. (Adorno, 2008, p.158) 
Procurando identificar a genealogia deste tabu, Adorno recorre às origens da profissão docente no limiar da Modernidade. Detecta, por exemplo, que em um determinado momento histórico, o docente começa a ser encarado como um sujeito tirano e que aplica castigos, exercendo seu lado despótico em relação ao estudante. Estabelece a hipótese "de que a imagem inconsciente de agente de castigos exerce maior influência sobre as representações relativas ao professor do que a própria prática de castigos físicos." (Adorno, 2008, p.167). Por outro lado, a hierarquização imposta pelas notas e pelos castigos reforçam este perfil, visto que muitos professores usam-nos como instrumento de reação à postura dos discentes.

Outros elementos contribuem para a manutenção deste tabu. Para Adorno, o fato de o docente se especializar cada vez mais, centrando seus estudos na profundidade de um determinado ramo do conhecimento, e não procurando conhecer aqueles que extrapolam as barreiras de sua formação professoral, incidem em uma formação limitada, trazendo consequências ao exercício da docência.

O tabu também é reforçado por conta de algumas limitações existentes na formação inicial dos professores, como, por exemplo, a análise que aponta a escola como um fim em si mesmo. Esta barreira faz com que a escola não se conecte com a sociedade, posicionando-a na condição de uma ilha social.

A própria profissão docente acaba sendo prejudicial ao próprio ato de educar, tendo em vista a percepção, principalmente por parte dos estudantes, que o professor detém uma autoridade intelectual inabalável. Este efeito maléfico, segundo Adorno, traz consequências nefastas para a educação, especialmente porque o professor exerce uma função fundamental para o processo civilizatório, algo diametralmente oposto à barbárie.

A barbárie é um estado em que fracassam todos os processos de formação desenvolvidos pela escola. É certo que, na medida em que a sociedade extrai de si a barbárie, a escola bem pouco pode opor resistência [...] A desbarbarização da humanidade é o pressuposto imediato de sua sobrevivência. A ela deve servir a escola, por 
limitados que sejam seu âmbito e suas possibilidades e, para tanto, precisa-se libertar dos tabus, sob cuja pressão se reproduz a barbárie. (Adorno, 2008, p.176)

A reflexão adorniana é válida na medida que o frankfurtiano compreende que a educação contribui para a emancipação individual, já que ela visa formar as pessoas para a civilidade, caminhando em direção oposta, portanto, da barbárie. Por outro lado, o tabu que cerca a profissão docente colabora com o estado bárbaro. Talvez isto explique o motivo que fez Adorno escrever sobre o tabu, especialmente porque identifica que ele é mais forte entre os estudantes.

É bom destacar que esta constatação feita por Adorno em torno da profissão docente se insere no contexto de uma crise educacional existente. No texto intitulado Teoria da semiformação, o frankfurtiano diagnostica que os ditos progressos da técnica não trouxeram o equivalente progresso ao aspecto cultural, chegando a afirmar que:

As desproporções resultantes da transformação mais lenta da superestrutura em relação à infraestrutura aumentaram o retrocesso da consciência. A semiformação assenta-se parasitariamente na cultural lag (demora cultural). (Adorno, 2010, p.27)

Assim, a formação, que para o autor permite ao indivíduo emanciparse, não se concretizou. Em outros termos, em vez de uma sociedade emancipada e esclarecida, as contradições oriundas do progresso técnico fecundaram o que Adorno denomina de semiformação socializada.

A premissa para essa situação reside em dois aspectos que se relacionam: 1) A burguesia, durante o seu processo revolucionário, se emancipou e consolidou sua formação cultural, formatando as bases para seu progresso espiritual. O proletariado, ao contrário, não caminhou pela mesma trilha ou foi impelido a isso; 2) As classes dominantes monopolizaram a formação cultural em uma sociedade vazia, o que 
acarretou a desumanização do próprio ser humano, tornando-o alienado. No caso da escola, a semiformação repercute nas:

Reformas escolares, cuja necessidade não se pode colocar em dúvida, descartaram a antiquada autoridade, mas também enfraqueceram mais ainda a dedicação e o aprofundamento íntimo do espiritual, a que estava vinculada a liberdade. (Adorno, 2010, p.21)

Esta situação constitui-se nos elementos fundantes do que ele denomina de semiculto, ou seja, o indivíduo conformado, que se dedica a conservar a si mesmo sem si mesmo, contribuindo com o que Adorno identifica como narcisismo coletivo. Outro aspecto destacado em relação ao semiculto diz respeito à experiência, que passa a ser desconectada, efêmera e desvinculada da sucessão dos fatos. A este respeito, o frankfurtiano chega a afirmar que a o semiculto tem orgulho de dizer que não consegue conectar os fatos ou se recordar de outros porque é muito ocupado.

Como se vê, a condição de semiformação identificada por Adorno é a pá de cal que fecha o diagnóstico da situação em torno da profissão docente. Se por um lado o professor é rodeado pelo tabu e submetido a um exame cheio de insuficiências, por outro, o ambiente cultural colabora com as dificuldades postas para a prática docente.

Embora a distância temporal e espacial seja real, é inegável que as reflexões adornianas tendem a contribuir com o diagnóstico da profissão docente em nosso país. A desvalorização da carreira do professor no Brasil faz com que uma parcela significativa da sociedade despreze a função docente, posicionando-a como uma profissão de segundo nível, destinada àqueles que não conseguem lograr êxito nas carreiras com maior valorização salarial. Por outro lado, percebe-se que os concursos públicos para professores, na maioria das vezes, valorizam o aspecto conteudista, estritamente técnico, dos conhecimentos filosóficos, algo que acaba depondo contrariamente contra a própria Filosofia. Além disso, por mais que haja o respeito à profissão docente, uma parcela significativa da 
sociedade a despreza, principalmente se for feita a comparação com outras carreiras profissionais, como a Medicina e o Direito.

Neste artigo, procurou-se sistematizar alguns dados que foram obtidos em diversos estudos, sejam eles qualitativos e/ou quantitativos, visando estabelecer um diagnóstico de situação, nos moldes expressos pelos teóricos críticos. Em seguida, buscou-se encontrar uma reflexão filosófica em torno da profissão docente que pudesse auxiliar a presente argumentação, solução esta encontrada nos textos educativos de Theodor Adorno. Os dados aqui arrolados expõem elementos importantes para se pensar a formação docente, particularmente a do professor de Filosofia na atualidade.

As informações, parece, que são pertinentes para refletir em torno de algumas indagações. Com base em Matos (2013, p.95): 1) Que necessidades sociais queremos e a elas podemos atender mediante nosso trabalho escolar?; 2) Quais os princípios que norteiam nosso trabalho de formação de educadores?; 3) Quais são as características que delineiam o perfil do filósofo que queremos formar como professor?

Para concluir, penso que a formação do docente de Filosofia deve considerar os elementos aqui postos, pois só assim esta formação cumprirá não apenas os desígnios conceituais do próprio termo formação (paideia $\mathrm{e}$ bildüng), como também possibilitará ao futuro professor exercer suas atribuições funcionais de forma emancipada e emancipatória. 


\section{Referências}

ADORNO, T.W. Educação e emancipação. Tradução Wolfgang Leo Maar. 3.ed. Rio de Janeiro: Paz e Terra, 2003.

ADORNO, T.W. Tabus a respeito do professor. In.: PUCCI, B.; OLIVEIRA, N.R.; ZUIN, A.A.S.; LASTÓRIA, L.A.C.N. (org.). Adorno: o poder educativo do pensamento crítico. 4.ed. Petrópolis: Vozes, 2008.

ADORNO, T.W. Teoria da Semiformação. In.: PUCCI, B.; ZUIN, A.A.S.; LASTÓRIA, L.A.C.N. (org.). Teoria Crítica e inconformismo: novas perspectivas de pesquisa. Campinas: Autores Associados, 2010.

BRASIL. Conselho Nacional de Educação. Define as Diretrizes Curriculares Nacionais para a formação inicial em nível superior (cursos de licenciatura, cursos de formação pedagógica para graduados e cursos de segunda licenciatura) e para a formação continuada. Resolução CNE/CP n. 2 de $1^{\circ}$ de julho de 2015. Brasília, 2015.

BRASIL. Conselho Nacional de Educação. Diretrizes Curriculares Nacionais para a Formação Inicial e Continuada dos Profissionais do Magistério da Educação Básica. Parecer n. 02/2015, aprovado em 9 de junho de 2015. Brasília, 2015.

BRASIL. Ministério da Educação. Censo da Educação Básica 2016: notas estatísticas. Brasilia: INEP, 2017. Disponível em < http://download.inep.gov.br/educacao basica/censo escolar/notas estatistic as/2017/notas estatisticas censo escolar da educacao basica 2016.pdf $>$. Acesso em: 23 de abril de 2017.

BRASIL. Censo da Educação Superior 2016: notas estatísticas. Brasília: INEP, 2017. Disponível em < http://download.inep.gov.br/educacao superior/censo superior/documentos L2016/notas sobre o censo da educacao superior 2016.pdf >. Acesso em: $1^{\circ}$ de setembro de 2017.

BRASIL. Censo escolar 2013: perfil da docência no ensino regular. Brasília: INEP, 2015.

BRASIL. Formação de professores do ensino médio. Caderno II: Ciências Humanas. Curitiba: EdUFPR, 2014.

BRASIL. Remuneração dos docentes em exercício na educação básica: um pareamento das bases de dados do Censo Escolar e da RAIS. Brasília, 2017. 
FAVERO, A.A. (et.al). O ensino de Filosofia no Brasil: um mapa das condições atuais. Caderno CEDES, Campinas, v. 24, n. 64, set./dez., p. 257284. 2004. Disponível em < http://www.cedes.unicamp.br/ >. Acesso em: 15 de agosto de 2016.

FUNDAÇÃO LEMMAN. Portal QEdu. Disponível em < http://qedu.org.br// >. Acesso em: 25 de novembro de 2017.

GALLO, S. Metodologia do ensino de filosofia: uma didática para o ensino médio. Campinas: Papirus, 2012.

GATTI, B.A. Educação, escola e formação de professores: políticas e impasses. Educar em Revista, Curitiba, n. 50, out./dez., p. 51-67. 2013. Disponível em < http://revistas.ufpr.br/educar/article/view/34740 >. Acesso em: 20 de maio de 2016.

IDADOS. Perfil dos Futuros Professores. Boletim IDados da Educação. Rio de Janeiro: Instituto Alfa \& Beto, 2016.

INSTITUTO DE PESQUISA ECONÔMICA APLICADA. Radar: tecnologia, produção e comércio exterior. n.32, abr. Brasília: Ipea, 2014.

MATOS, J.C. A formação pedagógica dos professores de filosofia: um debate, muitas vozes. São Paulo: Loyola, 2013.

NOBRE. M. (org.). Curso Livre de Teoria Crítica. 3.ed. São Paulo: Papiros, 2008. OCDE. Education at a Glance 2017: OCDE indicators. Paris: OCDE Publishing, 2017. Disponível em < http://www.oecd-ilibrary.org/education/education-ata-glance-2017 eag-2017-en >. Acesso em: 10 de novembro de 2017.

OLIVEIRA, P.R. A formação do professor de filosofia: entre o geral e o particular. Revista Sul-Americana de Filosofia e Educaşão. Brasília, n. 24: maio/out, p. 221-231, 2015. Disponível em < http://periodicos.unb.br/index.php/resafe/article/view/17468/0 >. Acesso em 15 de setembro de 2017.

RIBEIRÃO PRETO. CONSELHO MUNICIPAL DE EDUCAÇÃO. Parecer sobre o projeto de Lei Complementar que dispõe sobre o credenciamento de Professores Substitutos para ministrarem aulas avulsas surgidas na Rede Municipal de Ensino de Ribeirão Preto. Disponível em: < https://www.ribeiraopreto.sp.gov.br/seducacao/pdf/parecer 0701.pdf $>$. Acesso em: 15 de novembro de 2017. 
ROLIM, M. A formação de jovens violentos: estudo sobre a etiologia da violência extrema. Curitiba: Appris, 2016.

SAVIANI, D. Formação de professores no Brasil: dilemas e perspectivas. Revista Poiesis Pedagógica, Goiânia, v. 09, n. 01, p. 07-19, 2011. Disponível em: < https://www.revistas.ufg.br/poiesis/article/view/15667 $>$ Acesso em: 21 julho 2017.

SILVA, F.L. Currículo e formação: o ensino da Filosofia. Revista Sintese Nova Fase. Belo Horizonte, v. 20, n. 63, p.797-806, 1993. Disponível em: < http:// faje.edu.br/periodicos/index.php/Sintese/article/view/1301 >. Acesso em: 13 de maio de 2016.

VEIGA, I.P.A.; AMARAL, A.L. (org.). Formação de professores: políticas e debates. Campinas: Papirus, 2002.

Submetido em: 10/01/2018

Aceito em: 08/05/2018

Publicado em: 15/10/2018 